\title{
Memórias de Guerra: A narrativa da destruição como construtora da identidade europeia
}

\author{
War Memories: The discourse of Europe's \\ destruction as a key argument to construct identities
}

Luiz Fernando Horta*

\section{Resumo}

A Europa precisou ser reconstruída após a Segunda Guerra. Entretanto, esta reconstrução não foi física, mas sim identitária. Novos dados sobre a destruição europeia não chancelam a ideia de hecatombe que é oferecida para explicação do imediato pós-guerra. Assim, fica prejudicada a interpretação de que a Europa necessitava de ajuda externa para se reconstruir. Se a destruição material e produtiva da Europa é uma construção discursiva, a quê ou a quem este construto efetivamente serviu? Este texto afirma que o discurso da "destruiç̧ão/reconstrução" da Europa serviu para a construção da identidade da Europa Ocidental "de costas" à Oriental.

Palavras-chave: Europa; Identidade Nacional; Guerra Fria; Poder; Memória

\begin{abstract}
Europe had to be rebuilt after World War II. However, this reconstruction was not physical, but rather in its identity. New data on European destruction do not endorse the idea of catastrophe that is offered to the immediate postwar explanation. So it is impaired the interpretation that Europe needed outside help to be rebuilt. Since the physical and productive destruction of Europe is a discursive construction, to what or to whom this construct effectively had served? This text states that the discourse of "destruction/reconstruction" of Europe served to build the identity of Western Europe "on his back" to Eastern counterpart.
\end{abstract}

Key Words: Europe; National Identity; Early Cold War; Power; Memory

* Doutorando em História das Relações Internacionais pela Universidade de Brasília (UnB). E-mail: fernandohorta@unb.br 
A história é feita de discursos. Seja essa frase entendida no sentido do discurso apenas como representação da realidade ou mesmo como constitutivo desta. Nesse caso, a diferença de abordagem não retira a razão teórica da afirmação inicial. Tais discursos, entretanto, não podem ser entendidos como uma transcrição fidedigna do real, mesmo que se admita, através do paradigma moderno, que este real existe objetivamente. Além da temporalidade do discurso é importante também se ater aos objetivos implícitos ou explícitos do fazer discursivo. Em que tipo de conjunção sócio-histórica determinado discurso emerge e que tipo de conjunção sócio-histórica este discurso faz emergir (ou representa). É papel do historiador formular discursos e também questionar discursos sob a perspectiva epistemológica que conjugue fontes, contextos, interesses e objetivos": "The past, after all, is an argument, and ideally historians are able to purify public arguments, in the process "narrowing the range of permissible lies"'2 (MULLER, 2004, p. 23).

Esse trabalho questiona a congruência entre a afirmação corrente na literatura de uma Europa "destruída" no pós-segunda guerra e a evidência que pode ser colhida sobre o período. Não se trata aqui de negar o sentimento de destruição e sua legítima rememoração pelos cidadãos europeus que sobreviveram aos dois conflitos mundiais em um prazo de pouco mais de vinte anos. Não há que se argumentar, portanto, contra a memória individual (HABERMAS, 1988):

This image will need to be nuanced if we are to understand how the same shattered continent was able to recover so rapidly in years to come. (...) Europeans felt hopeless, they were exhausted - and for a good reason. ${ }^{3}$ (JUDT, 2005, p. 13) (grifo do original).

A memória coletiva, contudo, não pode ser entendida como um espelho da realidade e, tampouco, pode ser tomada como um construto passivo de determinada sociedade. A memória coletiva, pela mesma razão, tem tanta permeabilidade aos interesses de poder quanto qualquer outra construção histórica. E ao historiador cabe também analisá-la em busca de seus traços constitutivos, dos rastros de poder que têm o condão de transformar narrativas singulares em versões aceites e rememoradas pelos Estados Nacionais - com pompa e circunstância - em meio às criações e recriações do tempo presente.

Afirma-se aqui não só que a Europa não estava materialmente destruída (no sentido de "hecatombe"4 (JUDT, 2005, p. 9) que é comumente usado (LOWE, 2012, p. 13)) como a forja deste discurso permitiu a construção de uma identidade europeia (ocidental) "de costas"

1 "Thus, despite the intense focus on memory in history, sociology and cultural studies, the memory-power nexus remains curiously unexamined. (MULLER, 2004, p. 2) "Assim, apesar do intenso foco à memória que dão história, sociologia e os estudos culturais, o nexo entre memória e poder continua curiosamente pouco examinado. " (Todas as traduções apresentadas são de responsabilidade do autor do artigo)

2 "O passado, afinal de contas, é um argumento e os historiadores, de preferência, devem ser capazes de depurar os argumentos públicos de forma a diminuir o espaço das 'mentiras permitidas'."

3 "Esta imagem precisa ser matizada se quisermos entender como o mesmo destruído continente foi capaz de se recuperar tão rapidamente em poucos anos seguintes. (...) Europeus sentiram-se sem esperança, eles estavam exauridos - e com razão"

4 En el conjunto de Europa cientos de ciudades fueron parcial o totalmente arrasadas. Las fotografías tomadas después de la guerra pueden dar una idea del calibre de la destrucción de ciudades en particular, pero cuando se intenta multiplicar esta desolación por todo el continente escapa por fuerza a toda comprensión. (LOWE, 2012, p. 13). "Em toda a Europa centenas de cidades foram parcial ou totalmente arrasadas. As fotografias feitas depois da guerra podem dar uma ideia do calibre da destruição urbana em particular, mas quando se tenta multiplicar este nível de destruição por todo o continente esta percepção exacerba a própria compreensão." 
à Europa Oriental. Como evidências iniciais é possível argumentar (em caso de aceite a hipótese da hecatombe material (MILWARD, 1987)) que a reconstrução tão veloz e profícua da Europa (JUDT, 2005, p. 5) não se poderia ter dado apenas com irrigação financeira (Plano Marshall). Outras evidências podem ser apontadas como, por exemplo, o fato de durante o período de 1939-1945 a máquina de guerra alemã ter usado os parques industriais dos países dominados como forma de aumentar a sua (própria) força industrial (JUDT, 2005, p. 13-14). Lembrando que o uso se opõe à destruição.

Efetivamente, não interessava à Alemanha a destruição física da Europa (esta somente se dá no final da guerra, em 1944) (LOWE, 2012, p. 16) e, essencialmente (quase em sua totalidade), no eixo geográfico que compreende a parte oeste da Rússia, Polônia, Alemanha e norte da França (LOWE, 2012, p. 12-17). Se estes quatro países, nem de longe representam "toda" a Europa, eles têm, ainda, níveis de destruição diferentes se comparados entre si (EICHENGREEN, 2007, p. 55). Assim, o termo "destruição" deve ser relativizado caso a caso e se tomada a Europa pelo seu conjunto dificilmente se pode chancelar a tese da "hecatombe de guerra"5.

The first step in such a research strategy is to trace the origins of a particular set of collective memories and investigate the ways in which such memories became embedded in the culture and the political system. Since events do not speak for themselves, the analyst must explore the ways in which pivotal events in a nation's history are addressed by different groups in a society, especially political leaders and intellectuals. (MULLER, 2004, p. 82) ${ }^{6}$

À construção do discurso da "destruição" (física) da Europa se seguiu o discurso do ressurgimento desta mesma Europa (MORIN, 1987). Agora, porém, uma Europa que só agregava os países ditos "ocidentais" sem que nenhum critério lógico ou histórico fosse explicativo da diferenciação entre as "Europas". A legitimação da divisão era puramente volitiva reproduzindo uma dicotomia Oriente/Ocidente com algumas licenças poéticas de divisão por ideologia8, como, por exemplo, a diferenciação entre Áustria e lugoslávia (ambas na mesma posição de referência geográfica entre Oriente e Ocidente). O que de fato sucede é a construção de uma identidade de Europa Ocidental "de costas" para a Europa Oriental9:

5 Com exceção de Áustria, Grécia e Alemanha todos os outros países europeus atingiram em 1947 os mesmo índices de produção industrial do período imediatamente anterior à guerra (1938). Alguns países inclusive experimentaram crescimentos de quase $50 \%$ desses níveis como Turquia e Suécia. (EICHENGREEN, UZAN, et al., 1992, p. 17)

6 "O primeiro passo neste tipo de estratégia de pesquisa é traçar as origens de um determinado tipo de memórias coletivas e investigar as formas pelas quais tais memórias aparecem imiscuídas na cultura e no sistema político. Uma vez que os eventos não falam por si mesmos, o analista precisa explorar as formas pelas quais eventos centrais dentro da história de uma nação são utilizados por diferentes grupos desta sociedade, especialmente líderes políticos e intelectuais. "

7 Marc Abélès fala em "making Europe": "To the extent that "making Europe" appears a recent occupation, the expression "new cultural actors" might correctly apply to the communitarians of Brussels." (KASTORYANO, 2009, p. 32) "Sobre a ideia do "fazer a Europa' parecer ser recente a consideração sobre a expressão dos 'novos atores culturais' e deviam corretamente ser ligados aos comunitários de Bruxelas".

8 Para ver uma discussão da polissemia (e por isso mesmo a dificuldade de se usar o termo) do conceito de "Multiculturalismo" Riva Kastoryano (KASTORYANO, 2009, p. 4-10).

9 Segundo Yves Hersant: "Finally, they never stop invoking the culture of all of Europe, but de facto they privilege that of a Western minority. (...)." "Finalmente, eles nunca param de invocar a cultura de toda a Europa quando de fato estão privilegiando uma minoria ocidental (...)." 
Once asked about the patronage of the EEC, Paul-Henri Spaak answered that Stalin was its father, inasmuch as fear of the Soviet Union had provided the impetus to hang together rather than hang separately. (MULLER, 2004, p. 135)10

However, the lack of European civic identity risks leading to a definition of a European "us" founded on a social order as a common good, but as a space of prosperity and security founded more on exclusion (based on ethnic and religious criteria) than on inclusion. (KASTORYANO, 2009, p. 18)11

\section{0 papel da memória}

A memória não é o passado. A memória também não é história. A junção lógica entre estas duas frases nos levaria a pensar que a memória - sendo memória de algo que ocorreu efetivamente (por transcrição ou reconstituição interpretativa (RICOEUR, 2007, p. 31)) - se situa em algum lugar entre o passado e a história. Entretanto, assumir essa afirmativa apenas seria desconhecer o papel de duas forças que atuam sobre a memória. Em primeiro lugar, a memória não é uma forma passiva de apropriação da realidade. Rememorar é imaginar, como lembra Paul Ricoeur (RICOEUR, 2007, p. 25). A imaginação humana joga parte ativa na memória para além ainda de toda a capacidade de representação ou recriação construtiva que se faz a partir da linguagem (RICOEUR, 1997). São já dois níveis de subjetividade a jogar contra a cristalização da memória como um passado "que realmente aconteceu". A segunda força que atua sobre a memória é de origem externa ao indivíduo. Existe uma "batalha pela consciência dos homens" (ANDERSON, 1993, p. 67), no dizer de Benedict Anderson, que evidencia a relação entre memória e poder. Notadamente entre memória e poder político. É vasta a associação teórica que se faz entre a memória e as construções do imaginário nacional. Eric Hobsbawm afirma inclusive que "(...) para os propósitos da análise, o nacionalismo vem antes das nações. As nações não formam os Estados e os nacionalismos, mas sim o oposto" (HOBSBAWM, 1990, p. 19). 0 exercício oficial de se apropriar da memória tornando-a "memória coletiva" gera uma "identidade nacional" construída de cima para baixo pelos aparatos nacionais, antes de existente per se (MULLER, 2004, p. 3). É dessa amálgama discursiva entre o individual e o coletivo, entre a memória coletiva e o discurso nacionalista que avança (se constrói e se significa) a ideia de nação.

Este não é um processo racional ou lógico (HOBSBAWM, 1990, p. 17). As formas pelas quais o indivíduo se subordina à memória coletiva variam desde a criação de tradições (HOBSBAWM e RANGER, 1997, p. 10), até a construção de rebuscados sentimentos de diferenciações entre populações calcados, por exemplo, no ódio, na revanche ou na rivalidade:

\footnotetext{
10 "Quando perguntado sobre a fundação da Comunidade Europeia, Paul-Henri Spaak afirmou que Stalin foi seu pai da mesma forma que o medo da União Soviética criou o ímpeto para que se unissem ao invés de seguirem separados"

11 "Entretanto, a falta de uma identidade cívica europeia traz consigo o risco da formação do "nós europeus" baseada na ordem social não como um bem comum, mas como um espaço de prosperidade e segurança cuja base repousa mais na exclusão (baseado em critérios étnicos e religiosos) do que na inclusão"
} 


\begin{abstract}
Algunos historiadores han sugerido que los odios y las rivalidades entre grupos políticos y nacionales europeos antagónicos seguirán existiendo siempre que continuemos conmemorando los acontecimientos de la guerra y el periodo inmediatamente posterior. La deprimente reaparición de los odios nacionalistas en las dos últimas décadas podría indicarlo. (LOWE, 2012, p. 288)12
\end{abstract}

É neste campo, de um tempo que não se mistura com o passado apropriado, que o historiador também precisa se mover. Entender a formação dos discursos sobre acontecimentos de determinadas sociedades é fazer a história de um passado que é constantemente reinventado (MULLER, 2004, p. 9). Tal reinvenção pode se dar aleatoriamente nas memórias individuais, mas sua compilação responde a processos de poder quando são inseridas dentro dos discursos oficiais e tornam-se parte de uma "memória coletiva". Se ligadas à formação das "comunidades imaginadas" de Anderson, podemos efetivamente chamá-las de "memórias nacionais".

Não nos é permitido, entretanto, deixar de perceber o papel que tais memórias jogam dentro dos processos políticos de tempos mais modernos à sua criação. As decisões políticas tomadas no tempo presente refletem e são condicionadas pelas memórias nacionais.

But as in the West, memory has also played a role in foreign-policy-making, both in the sense that policy-makers themselves are casting around for historical analogies, and in the sense that foreign policies are legitimated on the grounds of historical experience. (MULLER, 2004, p. 10)13

Assumir as memórias coletivas como forma real do passado é um equívoco epistemológico, muito embora, em alguns contextos, a força política dessa memória, construída e sustentada pelos discursos nacionais (oficiais ou não), acaba criando uma "frozen history" (MULLER, 2004, p. 11), sobre a qual é quase um sacrilégio apor questionamentos. Apesar do componente psicológico da memória (MULLER, 2004, p. 19), é seu processo de coletivização/ nacionalização que Ihe confere poder. Sendo constitutiva de valores nacionais e formando as estruturas pelas quais os indivíduos se reconhecem enquanto partes de um todo, essas memórias chegam a formar uma verdadeira "cultura política" (MULLER, 2004, p. 26) que, além de informar os tomadores de decisão, ainda constrange os discursos de dúvida ou questionamento sobre a própria memória.

Esse uso público da história sob a forma de "memória oficial" é particularmente importante em sociedades sobre as quais recaiam pesos de culpa ou vitimizações (HABERMAS, 1988, p. 44). Nesse sentido, Jürgen Habermas aconselha uma "apropriação crítica" dessas memórias, não no sentido de selecioná-las através de alguma forma de moralidade histórica ou mesmo de constrição de consciência social, mas no sentido de refletir sobre o devido lugar dessas memórias no processo de constituição tanto do indivíduo quanto do coletivo nacional:

\footnotetext{
12 "Alguns historiadores têm sugeridos que os ódios e as rivalidades entre os grupos políticos e nacionais europeus antagônicos, continuarão a existir uma vez que se continue comemorando os acontecimentos da guerra e do momento subsequente. 0 triste reaparecimento dos ódios nacionalistas, ocorrido nas últimas duas décadas, poderia ser entendido desta forma. "

13 "Mas, assim como no Oeste, a memória tem também jogado um papel na política externa, tanto no sentido de que os tomadores de decisão buscam analogias históricas quanto na ideia de que políticas externas são legitimadas segundo bases de uma experiência histórica."
} 
Accordingly, without a memory of national history, which has been subjected to a "thought ban," we cannot create a positive image of ourselves. Without a collective identity, the argument continues, the forces of social integration would disappear. (HABERMAS, 1988, p. 45)14

É evidente que essa apropriação da memória individual pelo discurso oficial (quase sempre nacionalista), e consequente transformação em memória coletiva, não é uma atividade mecânica ou que possa ser delimitada objetivamente. Existe um processo de "negociação" da memória entre os coletivos sociais e o discurso nacionalista (NEUMANN, 1999, p. 110). 0 resultado dessa negociação - a formação da identidade nacional - é um processo ambíguo e frequentemente discrepante entre a posição dos diversos grupos (e sua autoformação identitária) e o discurso empoderado pelos detentores do poder decisório (político, social, econômico etc.) (HOBSBAWM, 1990, p. 162).

Nesse embate histórico-discursivo, o discurso oficial costuma direcionar as memórias coletivas, ressignificando-as no sentido da evidência das alteridades (em detrimento das similitudes geográficas, culturais, sociais etc.) como forma de reforçar a constituição de si. O discurso do "outro" como necessariamente não participante da história, da sociedade ou do esforço nacional empreendido (seja de sobrevivência, de revolução, de reconstrução ou qualquer outro) acaba gerando forças de coesão que agem de forma a aproximar os que se identificam (e são reciprocamente identificados pelo coletivo) como iguais e, ao mesmo tempo, afastar a todos os outros ${ }^{15}$.

Since region building can be seen as a kind of identity politics, in which participants try to forge an identity, it unavoidably involves accentuating similarities between self and other. Identification is as much about what one is not as about what one is. Group identity is not conceivable without an other from which the self can be differentiated. (NEUMANN, 1999, p. 148)16

\section{A formação da alteridade ${ }^{17}$ europeia}

Não é estranha à história da Europa a ideia da criação discursiva do "outro" como forma de delimitação de sua própria identidade. Em realidade, já na Antiguidade o conceito de "bárbaro", cunhado pelos gregos e usado pelos romanos, demonstra esta prática (FINLEY, 1983, p. 55). A

14 "Por conseguinte, sem a memória da história nacional, que tem sido objetivo de um tabu crítico, nós não conseguimos criar uma imagem positiva de nós mesmos. Sem a identidade coletiva, o argumento segue, as forças de integração social tendem a desaparecer."

15 Como lembra Eric Hobsbawm não há critério lógico positivo satisfatório para a construção da identidade de uma "nação". Não há um "passado histórico distinto" que possa ser evidenciado, não há uma condicionalidade geográfica, política ou cultural (HOBSBAWM, 1990, p. 16-18)

16 "Uma vez que a construção da região pode ser entendida como um tipo de política identitária, em que os participantes tentam criar sua identidade, isto, de forma inescapável, significa aumentar os laços de similaridade entre o "eu" e o "outro". Identificação é tanto sobre o que o outro não é, quanto sobre o que o outro é. Identidade coletiva não é compreendida sem o "outro" do qual o "eu" pode ser diferenciado."

17 Essa construção da alteridade copia, em grande parte, a ótica americana sobre política externa do período, em forma e conteúdo: "Exploring this critical policy concern also sheds light on a significant theoretical issue: prior efforts to achieve American engagement in the cause of world order entailed the role of imagery, ideas, and justifications." (RUGGIE, 1997, p. 92-93). "Entender esta preocupação política central é também lançar luz sobre uma significativa questão teórica: os primeiros esforços para alcançar o engajamento norte-americano na questão da ordem mundial traziam o papel do imagético, das ideias e justificações" 
alteridade, entretanto, não pode ser reduzida simplesmente a uma condição de superioridade da sociedade greco-romana aos bárbaros, sendo que era exatamente o ofício do historiador aproximar-se do conhecimento destes povos diferentes ${ }^{18}$. As sociedades europeias, entretanto, ao desenvolverem o conceito de "fronteira" - e com ela o medo de que esse "outro" viesse a ser um "perigo" (VERNANT, 1993, p. 329) - acabaram tendo uma atitude pendular com relação às comunidades externas. Ora havia o medo intrínseco da invasão gerando os discursos de ódio e preparação para uma guerra, ora havia o desejo de acomodação abrindo a possibilidade da integração por assimilação (MOMIGLIANO, 1971, p. 37).

Na contemporaneidade, o padrão parece manter-se:

These reactions mirrored the two pervasive representations of the Soviet Union of the Cold War period. The dominant version was of an Asiatic/barbarian political power that had availed itself of the opportunity offered by the Second World War to intrude into Europe by military means. In 1945, Churchill is said to have maintained, with reference to the Soviet Union, that the barbarians stood in the heart of Europe, and the following year Konrad Adenauer wrote to William Sollmann that "Asia stands on the Elbe". (NEUMANN, 1999, p. 102)19

Após a Segunda Guerra Mundial a Europa tornou-se a área mais sensível da política internacional. Ocorre que este interesse não é homogêneo por toda a região geográfica chamada Europa.

It is American policy that is now seen in a new light, at least by many historians. Increasingly the argument seems to be that U.S. leaders in 1945 did not really care much about eastern Europe - that their commitment to representative government in that region was surprisingly thin and that by the end of 1945 they had more or less come to the conclusion that the sort of political system the Soviets were setting up in that part of the world was something the United States could live with. (TRACHTENBERG, 2012, p. 71)20 (grifo nosso)

De alguma forma, era preciso reconstruir uma Europa (ANDERSON, 1993, p. 24). Contudo, que Europa deveria ser reconstruída, sob que bases e a que custo são, em última instância, escolhas políticas. A reconstrução da identidade europeia era motivo de disputa maior entre os vencedores da guerra (EUA, Inglaterra, URSS). O projeto inglês era o de manter seu domínio

18 "The notion of a barbaric wisdom gained consistency and acceptance among those who considered themselves Greeks. As early as the fifth and fourth centuries B.C. the Greek philosophers and historians had shown a keen interest in foreign doctrines and customs and had been inclined to recognize some value in them. (...) The intellectual influence of the barbarians was, however, felt in the Hellenistic world only to the extent to which they were capable of expressing themselves in Greek." (MOMIGLIANO, 1971, p. 7) "A noção sobre o conhecimento bárbaro ganhou consistência e aceitação entre aqueles que se consideravam gregos. Datando dos séculos V e IV a.C. os filósofos e historiadores gregos tinham mostrado um agudo interesse pelas doutrinas estrangeiras e seus costumes e tinham se inclinado pelo reconhecimento do valor destes. (...) A influência intelectual dos bárbaros era, entretanto, sentida no mundo Helenístico apenas na extensão dos que eram capazes de se expressar em grego. "

19 "Estas reações espelham duas representações dominantes sobre União soviética durante a Guerra Fria. A versão dominante era sobre uma potência política asiática e bárbara que permitiu a si mesmo usar a oportunidade da Segunda Guerra para invadir a Europa por meios militares. Em 1945 era dito que Churchill sustentava, com relação à União Soviética, que os bárbaros se mantinham no coração da Europa, e, no ano seguinte, Konrad Adenauer escreveu para William Sollmann que "a Ásia se mantém até o Elba".

20 "É a política Americana que é atualmente entendida sob novas perspectivas por muitos historiadores. De forma mais enfática, o argumento parece ser que os líderes americanos no pós-1945 não se importavam realmente com a Europa Oriental - uma vez que seu compromisso com os governos representativos daquela região era surpreendentemente fraco e que no final de 1945 eles chegaram a um consenso de que o tipo de sistema político que os Sovietes estavam configurando naquela parte do mundo era algo com o que os Estados Unidos poderiam conviver" 
imperial e projetar sua liderança sobre uma Europa integrada21 (MULLER, 2004, p. 101). Para isso era necessário manter a URSS fora de qualquer participação significativa dentro de qualquer que fosse a Europa redesenhada (DOBBS, 2012). Tal postura já tinha levado a estremecimentos bastante fortes entre americanos e ingleses, mesmo durante a operação Overlord (MILLET, 1946). Tal desentendimento se manifestou novamente durante as negociações de lalta: Winston Churchill, que já havia em outubro de 1944 feito reuniões bilaterais para dividir a Europa com Stalin (conforme o famoso memorando das "percentagens"), tentava, a todo custo, manter intocados seus interesses imperiais. Postura que contrastava abertamente com os interesses americanos expressados por Roosevelt que

(...) conducted a campaign aimed at eliminating European empires, again with strong domestic support, though he was restrained by the need to avoid weakening Britain's resolve in the war and to ensure British and French postwar cooperation. " (RUGGIE, 1997, p. 99)22

Para Roosevelt era mais importante manter a aliança de paz estabelecida durante a guerra do que ceder aos interesses imperialistas dos ingleses. Esta posição tornava-se cada vez mais difícil uma vez que Churchill tentava fazer valer sua condição de "aliado especial" dos norte-americanos e Stalin procurava estabelecer "zonas de segurança” geograficamente próximas à URSS. Num primeiro momento, entretanto, parecia que os projetos dos três poderiam ter um elemento comum. A ideia de que a Alemanha precisava ser mantida incapaz de se reconstruir (e reerguer seu nacionalismo e imperialismo) (MULLER, 2004, p. 67) levou, por parte dos americanos, à formação do Plano Morgenthau e, pela URSS, à percepção de Stalin de que a Alemanha não deveria ser dividida²3.

Entretanto, como sublinha Hobsbawm, a memória coletiva que poderia dar forma à reconstrução nacional da Europa estava muito mais próxima dos movimentos de esquerda, no que o autor chama de "nacionalismo antifascista" (HOBSBAWM, 1990, p. 174-175). A explicação advém do fato de os governos europeus terem claramente escolhido o apoio ao capitalismo durante o período entreguerras (HOBSBAWM, 1990, p. 160) e, no pós-guerra, o capitalismo estar mnemonicamente ligado ao nazismo e fascismo (MULLER, 2004, p. 187-192). Além disso, os movimentos de resistência ao nazifascismo tinham sido majoritariamente liderados por comunistas (HOBSBAWM, 1995, p. 165-167), e em toda a Europa24. A presença comunista na Grécia, na Itália e na França eram não só evidentes como bastante fortes politicamente.

21 Whatever the case, Europe has been asked to invent an original method to erect its political unity, as soon as the discussion of the advantages and disadvantages of the constructivist-statist model (which was presumed to found the national principle) is over (KASTORYANO, 2009, p. 182)

22 “ (...) conduziu uma campanha que objetivava eliminar os impérios europeus, novamente com forte apoio interno, apesar de estar restringido pela necessidade de não enfraquecer o ímpeto da Inglaterra na guerra e de assegurar a cooperação com França e Inglaterra depois do conflito."

23 Os planos soviéticos para a Europa são bastante divergentes. Desde a ideia de Trotsky sobre a construção dos Estados Unidos da Europa (TROTSKY, 1923) até a postura favorável quanto à divisão em "esferas de influência" de Stalin é possível perceber uma postura ambígua soviética entre o desejo de aumentar a ingerência na Europa e o reconhecimento da oposição que faziam a isso Inglaterra e os próprios EUA. (DOBBS, 2012)

24 Na França a existência da França de Vichy e a não presença de de Gaulle em lalta corroboram para a proximidade com as esquerdas (MULLER, 2004, p. 61-62). Na Itália, a liberação tendo sido feita por levantes internos dos italianos se mistura com o sentimento anti-fascista para potencializar o apoio às esquerdas (MULLER, 2004, p. 223-225). 
Mais do que por uma reconstrução europeia, era preciso lutar pelos "corações e mentes" dos europeus evitando que o fato de a URSS ter sido a grande responsável pela vitória sobre os nazistas 25 viesse a fazer mais peso na memória europeia do que as negociações de lalta ou Potsdam. Era preciso a construção do discurso da alteridade. Era preciso demonstrar que o "outro" era suficientemente diferente do "eu", chancelando assim a divisão da Europa em duas: Europa Ocidental e Europa Oriental. A Europa Ocidental cria toda uma retórica em torno de "valores comuns" como "democracia" e "direitos humanos", mesmo ignorando que parte significativa dessa Europa vivia sob regimes ditatoriais (como os de Salazar e Franco).

As Ferry rightly remarks, Europe is constructed from the accomplishments of national political cultures that have integrated the normative implications of democracy and the rule of law that we find in constitutions and in their conception of human rights. (KASTORYANO, 2009, p. 12)26

Os norte-americanos precisavam incluir nesse rol de memórias criadas a ideia do "livre mercado" e os europeus precisavam dirimir as grandes cizânias (entre França e Alemanha, Inglaterra e Alemanha) e também as pequenas27 (questões étnicas internas à Europa como a questão basca, catalã, escocesa, a França de Vichy e etc.) (KASTORYANO, 2009, p. 13). Tal processo de criação e recriação das memórias se inicia com o Plano Marshall e segue até os dias de hoje, passando necessariamente pela Conferência de Copenhagen (1973) e pelo tratado de Maastricht (1992) (KASTORYANO, 2009, p. 46)28.

Witness the adoption at the Copenhagen Summit of 1973 of a Declaration on European Identity: an identity defined by "attachment to common values and principles," by the "rapprochement of conceptions of living," by the "consciousness of possessing specific interests in common. "In the minds of the signatories, it was to preserve itself both as civilization and as culture that Europe should be constructed; defending the patrimony, even outside national frameworks, became a mission of salvation. (KASTORYANO, 2009, p. 61)29

25 Esta percepção encontra-se na maioria das obras sobre o tema e é abertamente mencionada por Hobsbawm em entrevista a Geneton Moraes Neto em 01/10/2012 "Sem a União soviética, não teríamos vencido a Segunda Guerra" (disponível em http://g1.globo.com/ platb/geneton/2012/10/01/eric-hobsbawm-pecado-capital-do-capitalismo-e-injustica-social-pecado-capital-do-socialismo-foi-afalta-de-liberdade-mas-ainda-ha-um-vasto-espaco-para-o-sonho/).

26 "Como Ferry corretamente menciona, a Europa é construída a partir de realizações nacionalistas de caráter político-cultural que têm assumido as implicações normativas sobre democracia e o "estado de direito" que encontramos nas constituições, além da sua concepção de direitos humanos"

27 But these same nation-states are also confronted by an internal rise in minoritarian cultural, ethnic, and regional assertions that oppose both a Europe considered no longer as liberal but as technocratic and unifying, and well as states judged to be centralizing, both of which are equally ignorant of the specificities of such groups. (KASTORYANO, 2009, p. 198) "Mas estes Estados-Nações são também confrontados pelo surgimento interno de minorias culturais, étnicas e regionais cujos argumentos se opõem tanto a Europa que é considerada não mais liberal mas sim tecnocrática e unificada, quanto se opõem ao processo de centralização. Tanto os Estados quanto a Europa são igualmente ignorantes quanto as especificidades de tais grupos. "

28 Nesse sentido, da construção da ideia de Europa através das memórias, é evidente o interesse na UE em manter o controle sobre o que é ensinado dentro dos limites da comunidade. Esse domínio das memórias é reforçado pela ideia do "capitalismo impresso" de Benedict Anderson (ANDERSON, 1993) e da "bouillon de culture" de Edgar Morin (MORIN, 1987). "This voluntarist arrangement by the state is the central point for the political construction of modern nations, such that one could define the state as that ensemble of central institutions holding the "monopoly of legitimate education." (KASTORYANO, 2009, p. 164) "Este voluntarista acordo feito pelo Estado é o ponto central para a construção política das nações modernas, isto é tão evidente que se poderia definir o Estado como o conjunto de instituições centralizadas que tem o 'monopólio legítimo da educação'".

29 "Testemunhando a adoção, na conferência de Copenhague de 1973 da Declaração da Identidade Europeia: uma identidade definida pelo 'compromisso comum aos valores e princípios' pela 'aproximação dos conceitos de vida' e a 'consciência de possuir interesses específicos comuns'. No entendimento dos signatários isto servia para preservar eles mesmos tanto quanto entidade civilizacional, 
A Europa Ocidental se constrói no pós-Guerra com o discurso de que: "Of course we in Western Europe share almost the same fundamental political values" (KASTORYANO, 2009, p. 188) ${ }^{30}$, materializando as memórias inventadas e naturalizando valores díspares sob a ideia de um "estilo de vida" e uma "percepção de mundo" que seriam propriamente europeias (KASTORYANO, 2009, p. 221). Estes "artefatos culturais" (ANDERSON, 1993, p. 21) que formam a comunidade imaginada (ANDERSON, 1993, p. 23) da União Europeia têm uma dupla função de dar coesão aos "de dentro" e excluir "os de fora". Esta divisão é uma construção política sobre um discurso de alteridade e não o reconhecimento de algum padrão previamente existente.

It aims instead at a certain cultural and political unity and asserts itself more by the defensive refusals with which it confronts those who want to enter it than by any desire for conquest. Entry is selective and conditional. The admission of southern European countries made the countries of Eastern Europe after the fall of the Berlin Wall dream of the same fortune, an identical recognition that would mean both the benefit of a new Marshall Plan and their democratic choices taking root. But their integration already posed the problem of reconstructing the mechanisms of the Union's functioning to conserve a power of decision making that is concentrated for the benefit of a central kernel. (KASTORYANO, 2009, p. 222) ${ }^{31}$

A construção da alteridade europeia arranja as memórias do pós-guerra que the são favoráveis, agindo politicamente sobre o processo de constituição da comunidade. A guerra e os esforços de superação tornam-se assim um "destino" que coloca à prova a força da comunidade recém-criada, ao mesmo tempo em que demonstra a "fraqueza" daquelas comunidades que sucumbiram.

Si se concede generalmente que los estados nacionales son "nuevos" e "históricos", las naciones a las que dan una expresión política presumen siempre de um pasado inmemorial, y miran a un futuro ilimitado, lo que es aún más importante. La magia del nacionalismo es la conversión del azar em destino. (ANDERSON, 1993, p. 29)32

A Europa Oriental se forma, portanto, pela exclusão por parte dos ocidentais.

Por outro lado, os modelos de construção das memórias em relação ao Oriente se dão basicamente da mesma forma que no Ocidente (LOWE, 2012, p. 213). Historiadores e políticos depuram o conteúdo do passado para servir aos propósitos de coesão e afastamento criando as nacionalidades (MULLER, 2004, p. 9). Em realidade, mesmo que a alteridade

como quanto entidade cultural que a Europa deveria ser construída para defender tal patrimônio que apesar de estar fora das fronteiras nacionais havia se tornado uma espécie de "missão de salvação" do que era a Europa."

30 "É claro que nós da Europa Ocidental comungamos dos mesmos valores políticos fundamentais"

31 "Isto é direcionado não a certa unidade política e cultural (positiva) mas se coloca mais numa posição defensiva de recusa com o qual se confronta àqueles que querem entrar (na comunidade) de forma mais clara do que qualquer interesse de imposição de valores. A entrada (na comunidade europeia) é condicionada e condicional. A admissão dos países do sul europeu fez os países da Europa Oriental, depois da queda do muro de Berlim, sonharem com a mesma sorte, de um reconhecimento idêntico que significaria tanto o benefício de um novo Plano Marshall quanto suas escolhas democráticas serem fortalecidas. No entanto, esta integração já encontra o problema de que a reconstrução dos mecanismos da União serve para conservar o poder decisório que é concentrado em benefício de um núcleo central de países"

32 "Se se entende, de forma geral, que os Estados Nacionais são "novos" e "históricos", as nações (em si), que dão uma expressão política (aos Estados) presumem sempre um passado imemorial e visam um futuro ilimitado, o que é ainda mais importante. A magia do nacionalismo é a conversão do azar em destino. " 
agora seja representada em outros termos (do Oriente em relação ao Ocidente), construção discursiva da dicotomia capitalismo/comunismo, ignora as nuances e tende a reificar posições socioeconômicas modelares que, em realidade, nunca existiram. Tanto no mundo ocidental existiram diferenças gritantes na forma dos "capitalismos" quanto no "mundo oriental" os "socialismos" também obedeceram a modelos bastante peculiares. O fato é que é preciso diferenciar para empoderar o discurso de formação nacional.

This dichotomy between democratic and totalitarian or authoritarian replaced the master dichotomies civilized/barbarian and European/Asian and had affinities to a number of others such as free/unfree, market/plan, West/East, defensive/offensive. (NEUMANN, 1999, p. 103) 33

A recuperação das memórias inventadas serve para retomar a dicotomia-base da Antiguidade como forma de colocar a memória na condição de legitimar uma "alteridade moral" Ocidente/Oriente (NEUMANN, 1999, p. 122). O que se pode perceber é um discurso justificativo e normativo da diferença referendando posições políticas contemporâneas (democracia/ditadura, liberdade/opressão etc.) e deixando as manifestações em contrário dentro da "frozen history" de modo a que não se tenha dúvida da retidão das escolhas contemporâneas, nem ocidentais nem orientais.

Western Europe is already afloat in a sea of mis-memories about its own pre-1989 attitude towards communism. Whatever they now say, the architects and advocates of a unified Europe à la Maastricht never wanted to include a whole group of have-not nations from the east; they had yet fully to digest and integrate an earlier Mediterranean assortment. (MULLER, 2004, p. 180) 34 $^{34}$

Contudo, se na parte ocidental esse processo foi feito à maestria e culminou na planejada Comunidade Europeia, na Europa Oriental os discursos de compleição e suficiência que eram exarados no Ocidente abriram uma importante brecha política. As elites dos países limítrofes à URSS, com a ajuda do Ocidente, criaram uma "Europa Central". Uma nova forma identitária que se distinguia tanto do Ocidente quanto da URSS (MULLER, 2004, p. 10). A tentativa de se diferenciar tanto do oeste quando do leste tinha motivos distintos para cada uma das orientações (NEUMANN, 1999, p. 149), entretanto, demonstrava a impossibilidade de um sistema político bipolar encapsular os processos de formação e construção de identidades.

This memory ["Central Europe"] was used in order to differentiate this territory from the former Soviet Union, and also from the Balkans. Second, if it was possible for this alternative memory of the territory as qualitatively different from the former Soviet Union to be accepted

33 "Esta dicotomia, entre estados democráticos e totalitários ou autoritários se colocou no lugar das arquetípicas dicotomias entre civilizados/bárbaros e entre europeus/asiáticos e tem afinidades com inúmeras outras como o mundo livre/não livre, a economia de mercado/planificada, o Oeste/Leste e o defensivo/ofensivo."

34 "A Europa Ocidental está já boiando num mar de falsas memórias sobre sua própria atitude frente ao comunismo antes de 1989. Seja o que quer que se diga hoje, os arquitetos e advogados da Europa unificada 'à la Maastricht' nunca quiseram incluir todo o grupo das nações vindos do leste. Eles recém digeriram a integração das nações mediterrânicas. " 
by 'the West', it was because the dominant memory of Russia in Western discourse was informed by memories of Russia as a backward country and a potential military threat. (MULLER, 2004, p. 121) ${ }^{35}$

A construção de uma Europa Ocidental "de costas" para a Europa Oriental de forma a reproduzir a lógica bipolar encontra oposições dentro desta mesma Europa demonstrando que as identidades não são totalmente manipuláveis "pelo alto" e, essencialmente, que existiam memórias coletivas de uma Europa diferente da Europa bipolarizada. A "Europa Central" é uma pequena, mas significativa evidência conceitual.

\section{0 discurso da destruição da Europa}

Benedict Anderson aponta para a necessidade da "criação" (como esforço inventivo) de memórias. Esses mitos (LOWE, 2012, p. 285) fundacionais precisam estar contidos, embora não de forma precisa, nas memórias individuais para que possam ser elevados à condição de uma memória coletiva, cujo objetivo é o substrato da formação da identidade nacional e dos discursos nacionais. Tais discursos aliados a essa memória vão legitimar as escolhas políticas contemporâneas, indicando os caminhos a serem seguidos ou evitados. Não há como desqualificar a Segunda Guerra Mundial como este mito fundador desta nova Europa (HOBSBAWM, 1995, p. 58). O grau de provação a que a comunidade que está sendo criada sofreu tem relação positiva com a força dos laços de coesão identitária que serão construídos. Assim, a "destruição" da Europa se enquadra exatamente nesse tipo de "frozen history" que serve, em última instância, de base para a formação dos discursos nacionais. E, ainda que o Ocidente tenha transmutado a ideia de "inimigo" da Alemanha Nazista para a URSS comunista de forma satisfatória aos seus interesses políticos, as memórias individuais não são tão facilmente apagadas (HABERMAS, 1988).

São conhecidos e eloquentes os discursos sobre a "Europa devastada" depois da guerra, tanto em profundidade de devastação quanto em alcance. Para Hobsbawm "(...) a perda de recursos produtivos foi pesada, inteiramente à parte da queda do trabalho da população (...)" (HOBSBAWM, 1995, p. 55). Para Paul Kennedy, “(...) o mundo estava exaurido pela guerra (...) (KENNEDY, 1989, p. 343) enfatizando o caráter totalizante da percepção aduzindo ainda a "(...) devastação em que se encontrava a maioria dos rivais comerciais da Inglaterra (...)" (KENNEDY, 1989, p. 352) promovendo um "eclipse" de potências europeias (Idem, 353). Keith Lowe é bem mais minucioso, descrevendo sobre o estrago causado pelas "toneladas de bombas" que caíram sobre a Europa ele afirma:

En el conjunto de Europa cientos de ciudades fueron parcial o totalmente arrasadas. Las fotografías tomadas después de la guerra pueden dar una idea del calibre de la destrucción

\footnotetext{
35 "Esta memória [da Europa Central] foi usada como forma de diferenciação desta região para com a antiga União Soviética e também dos Bálcãs. Depois, isto só foi possível por causa de uma memória alternativa que afirmava que estes territórios, que eram diferentes da União Soviética, poderiam ser aceitos pelo Oeste. Isto causado essencialmente pelo fato de a memória dominante sobre a Rússia nos discursos Oeste ser formada pela memória de uma Rússia como um país atrasado e uma ameaça político-militar. "
} 
de ciudades en particular, pero cuando se intenta multiplicar esta desolación por todo el continente escapa por fuerza a toda comprensión. (LOWE, 2012, p. 13)36

Não se trata aqui de afirmar que não houve destruição material. Trata-se de depurar a memória com base na história. Tais discursos se tornaram a mola mestra da reconstrução da Europa de modo que mesmo cidadãos de países que não participaram da guerra (como Portugal, Espanha ou Suíça) reproduzem-no da mesma forma totalizante e profunda (LOWE, 2012, p. 14-17). Os dados empíricos, entretanto, mostram uma realidade muito diferente.

A Segunda Guerra teve a condição de ser uma guerra contra a população civil. Sejam as movimentações do exército nazista, do exército vermelho ou os bombardeios dos aliados todos os movimentos atingiram sobremaneira a população civil e produziram destruição de estradas, meios de comunicação e moradias (LOWE, 2012, p. 139). Contudo, o eixo da devastação se concentrou no que se chamou de Europa Oriental e Alemanha.

En el centro de toda esta destrucción se encuentra Alemania, cuyas ciudades sufrieron sin duda el perjuicio más completo de la guerra. (...) En términos absolutos, el daño a dichos espacios fue casi 18 veces mayor que en Gran Bretaña. (...). Según las cifras de la Oficina Estadística del Reich, Berlín perdió más del 50\% de los locales habitables, Hanóver el $51,6 \%$, Hamburgo el $53,3 \%$, Duisburgo el $64 \%$, Dormund el $66 \%$ y Colonia el $70 \%$. (LOWE, 2012, p. 14) $)^{37}$

Não só o Ocidente foi o menos atingido, como os danos não foram homogêneos em todos os países. Afora os países que não participaram da guerra (antes mencionados), a França de Vichy, o norte da Itália, a Suécia, entre outras áreas, passaram quase ilesas pela guerra. A destruição real se dá a partir de 1944 (LOWE, 2012, p. 16). Era estratégia alemã a anexação dos parques industriais dos países dominados como forma de impulsionar a Wehrmacht. Se olharmos para os danos sobre a capacidade produtiva dos países, o termo "devastação" se torna claramente equivocado (EICHENGREEN, 2007, p. 52)

As pesquisas empíricas atuais mostram que a destruição extensiva foi superficial para o processo de produção. Alan Milward, por exemplo, mostra que entre 1945 e 1947 (antes do Plano Marshall) apenas 14\% dos recursos do ERP (European Recovery Program) foram usados para compra de produtos de ferro ou aço (MILWARD, 1987, p. 77). Tal dado corrobora a ideia de que os danos não foram extensivos aos meios produtivos. A destruição foi muito maior para a população civil que se viu privada de água potável, aquecimento, energia elétrica (BLACK, 2003, p. 276)38. Estes fatos têm forte impacto na formação das memórias individuais. (EICHENGREEN, 2007, p. 54-55).

36 "Em toda a Europa centenas de cidades foram parcial ou totalmente arrasadas. As fotografias feitas depois da guerra podem dar uma ideia do calibre da destruição urbana em particular, mas quando se tenta multiplicar este nível de destruição por todo o continente esta percepção exacerba a própria compreensão. "

37 "No centro de toda esta destruição se encontra a Alemanha cujas cidades sofreram, sem dúvida, o prejuízo mais completo da guerra. (...) Em termos absolutos, o dano a estes espaços foi 18 vezes maior que sobre a Grã-Bretanha (...). Segundo os números da Oficina do Estado do Raich, Berlim perdeu mais de 50\% dos locais habitáveis, Hanover 51,6\%, Hamburgo 53,3\%, Duisburgo 64\%, Dortmund $66 \%$ e Colonia 70\%."

38 Ainda assim cidades como Paris e Praga, por exemplo, não foram bombardeadas (BLACK, 2003, p. 278) 
Do ponto de vista empírico, os dados atuais não chancelam o uso da ideia de "devastação" para o âmbito de toda a Europa. Os únicos países que efetivamente foram "devastados" foram a Alemanha, Polônia e URSS. Curiosamente nenhum deles figurava incialmente no conjunto a ser criado de "Europa Ocidental". Em termos populacionais, por exemplo, dentre os dez países com maior percentual de mortes em relação à sua população, apenas Holanda (com 2,4\%) e França (com 1,9\%) figuram como "ocidentais", e ainda em oitavo e décimo lugar, respectivamente ${ }^{39}$, na escala de perdas. A Polônia teve $17,2 \%$ da sua população dizimada durante a segunda guerra. URSS teve 14,2\%, Iugoslávia 11\% e Alemanha 8,8\%.

Se formos buscar dados empíricos sobre a destruição material, maior ficará ainda a dificuldade de conceder à memória da "devastação ocidental" algum crédito:

Table 1. Indexes of industrial production in Western Europe $(1938=100)$

\begin{tabular}{|c|c|c|c|c|c|c|}
\hline Country & 1947 & 1948 & 1949 & 1950 & 1951 & $\begin{array}{c}\text { Percentage } \\
\text { increase } 1951 \text { over } 1947\end{array}$ \\
\hline Turkey & 153 & 154 & 162 & 165 & 163 & 7 \\
\hline Sweden & 142 & 149 & 157 & 164 & 172 & 21 \\
\hline Ireland & 120 & 135 & 154 & 170 & 176 & 46 \\
\hline Denmark & 119 & 135 & 143 & 159 & 160 & 35 \\
\hline Norway & 115 & 125 & 135 & 146 & 153 & 33 \\
\hline UK & 110 & 120 & 129 & 140 & 145 & 32 \\
\hline Belgium & 106 & 122 & 122 & 124 & 143 & 33 \\
\hline Luxembourg & - & 139 & 132 & 139 & 168 & - \\
\hline France & 99 & 11 & 122 & 123 & 138 & 39 \\
\hline Netherlands & 94 & 114 & 127 & 140 & 147 & 56 \\
\hline Italy & 93 & 99 & 109 & 125 & 143 & 54 \\
\hline Greece & 69 & 76 & 90 & 114 & 130 & 88 \\
\hline Austria & 55 & 85 & 114 & 134 & 148 & 269 \\
\hline Germany (Federal Republic) & 34 & 50 & 72 & 91 & 106 & 312 \\
\hline All participating countries & 87 & 99 & 112 & 124 & 135 & 55 \\
\hline $\begin{array}{l}\text { All participating countries exclusive } \\
\text { of Cermany (Federal Republic) }\end{array}$ & 105 & 119 & 130 & 138 & 145 & 37 \\
\hline
\end{tabular}

Source: US President, First Report to Congress on the Mutual Security Program (31 December 1951), p. 75. Drawn from Brown and Opie (1953), p. 249.

Fonte: (EICHENGREEN, UZAN, et al., 1992, p. 17).

A tabela acima é extraída do Estudo de Eichengreen et al. e mostra que já em 1947 (pouco mais de um ano depois do final da guerra e ainda antes do Plano Marshall) apenas Grécia, Áustria e Alemanha ainda não haviam conseguido retornar às suas produções industriais aos

39 http://www.spiegel.de/international/europe/bild-645707-9748.html 
níveis do pós-guerra. Notadamente uma grande quantidade de países (ocidentais) haviam, em realidade, crescido.

\section{Conclusão}

O papel da memória é central para a formação das identidades nacionais. Entretanto, esta memória não necessariamente corresponde àquilo que um historiador metodologicamente teria construído sobre o passado que analisa a título de "história". A memória é fugidia e responde tanto aos componentes psicológicos individuais quanto às estruturas de poder que buscam legitimar-se nas memórias individuais como forma de construção de uma memória coletiva (muitas vezes alçada à condição de nacional). Tal construção acaba servindo de substrato para referendar as tomadas de decisão dos governos (interna e externamente) e, por isso mesmo, não há nada de passivo no processo de formação da memória ou mesmo no processo de formação de identidade. Estas comunidades imaginadas, na consagrada expressão de Benedict Anderson, vivem de construções de mitos e, portanto, são parasitas da história.

Os problemas começam quando essas memórias se travestem de verdade irretocável. Sobre as quais não se pode questionar. Esta "frozen history" torna-se um conjunto de discursos cimentado que não só constrangem o historiador, como impõem a toda sociedade uma "tirania das ideias" a-histórica. O papel de descobrir como estas ideias tomam forma política e mudam materialmente o mundo vem ganhando campo desde uma perspectiva mais crítica, que toma o materialismo histórico pelo seu avesso e o positivismo lógico pela sua oposição.

A julgar pelas evidências apresentadas nesse trabalho, nem a Europa Ocidental foi "devastada" - especialmente tomando-se a amplidão e profundidade do termo nos discursos nem sua reconstrução era impossível sem a ajuda norte-americana (Plano Marshall). 0 que levou ao uníssono dos discursos entre EUA e Europa Ocidental, a ponto de criarem uma "devastação europeia" e, em seguida, uma "reconstrução benevolente" cujos salvadores vinham do outro lado do Atlântico, foi uma rara confluência de interesses. Enquanto os americanos queriam manter o mundo como um lugar de livre-comércio, até para aproveitarem ao máximo as vantagens históricas que tinham, os Europeus precisavam afastar de vez o fantasma dos nacionalismos que haviam levado a tantos conflitos durante o século XIX e XX. Era necessário se refundar a identidade europeia passando por cima das dicotomias históricas como as cizânias entre França e Inglaterra ou entre França e Alemanha. Ao mesmo tempo, era necessário (aos olhos ocidentais) refundar uma Europa em termos divergentes da URSS.

O mito fundador dessa nova identidade estava posto. A própria guerra servia. Desde que a memória da Alemanha fosse reconstruída e um novo inimigo europeu fosse encontrado. Assim, a narrativa de uma Europa Ocidental despedaçada objetivava legitimar a necessidade de uma ajuda externa, bem como oferecer ao campo das "memórias individuais" espaços para o surgimento de forças de coesão entre os sujeitos que haviam "sofrido" as agruras da guerra. A toda destruição torna-se inerente um processo de reconstrução. E esse ciclo ideacional de destruição-reconstrução da Europa serviu para formar as bases de uma nova identidade. Esta identidade tinha que vir lastreada em valores que Ihe aproximassem dos EUA e a afastasse da 
URSS. Construiu-se uma Europa democrática que aceitava Franco e Salazar, mas não Stalin e Tito. Construiu-se uma ideia de representatividade e democracia que expulsava políticos eleitos pelos partidos comunistas dos governos que participavam. Enfim, construiu-se um modelo ideal de Europa que não correspondia efetivamente à realidade.

Este é um exemplo de que o mundo material só faz sentido através do esforço interpretativo. E esse esforço não é passivo. Criamos e recriamos memórias e discursos que vão dar forma ao mundo muito mais do que estar presas (essas memórias e discursos) à materialidade objetiva. No caso europeu a escolha pela narrativa da devastação tinha como propósito a criação de uma nova realidade no continente. Como se a Europa tivesse a oportunidade de um novo começo. Algo que deixasse a Guerra do Cem Anos (1337-1453), a Guerra dos 30 anos (1618-1648), a Revolução Francesa (1789-1799), a Guerra Franco-Prussiana (1871) e as Guerras Mundiais definitivamente fora dos novos processos identitários. Tal construção, embora tenha servido aos propósitos previstos durante a Guerra Fria, não mais contém o caleidoscópio das memórias nos campos das identidades "ocidental" e "oriental". O tempo dos matizes sólidos acabou.

\section{Bibliografia}

ANDERSON, B. Comunidades Imaginadas: Reflexiones sobre la origem y la difusión del nacionalismo. Ciudad de Mexico: Fondo de Cultura Económica, 1993.

BLACK, J. World War Two: A military history. New York: Routledge, 2003.

DOBBS, M. Six Months in 1945: FDR, Stalin, Churchill and Truman from world war to cold war. New York: Kindle Edition, 2012.

EICHENGREEN, B. The European Economy since 1945: coordinated capitalism and beyond. New Jersey: Princeton University, 2007.

EICHENGREEN, B. et al. The Marshall Plan: Economic Effects and implications for Eastern Europe and the former USSR. Economic Policy, v. 7, n. 14, p. 13-75, Abril 1992.

FINLEY, M. I. Politics in Ancient World. Cambridge: Cambridge PRess, 1983.

HABERMAS, J. Concerning the Public Use of History. New German Critique, n. 44, p. 40-50, OutonoVerão 1988.

HOBSBAWM, E. Nações e Nacionalismo desde 1780. Rio de Janeiro: Paz e Terra, 1990.

HOBSBAWM, E. A era dos Extremos: O breve século XX 1914-1991. São Paulo: Cia das Letras, 1995.

HOBSBAWM, E.; RANGER, T. A invenção das tradições. Rio de Janeiro: Paz e Terra, 1997.

ISAACSON, W.; THOMAS, E. The Wise men: Six friends and the world they made. New York: Kindle Edition, 2013.

JUDT, T. Postwar: A History of Europe since 1945. New York: Penguin Press, 2005.

KASTORYANO, R. An Identity for Europe: The relevance of multiculturalismo in EU construction. New York: Palgrave Macmillan, 2009. 
KENNEDY, P. Ascensão e queda das grandes potências. Rio de Janeiro: Campus, 1989.

LOWE, K. Continente Salvaje: Europa después de la Segunda Guerra Mundial. Madrid: Galaxia Gutemberg, 2012.

MILLET, J. World War II: Post-Mortem Begins. Political Science Quaterly, v. 61, n. 3, p. 321-348, Setembro 1946. MILWARD, A. S. The Reconstruction of Western Europe 1945-1951. New York: Routledge, 1987.

MOMIGliANO, A. Alien Wisdom: The Limits of Hellenization. Cambridge: Cambridge Press, 1971.

MORIN, E. Penser l'Europe. Paris: Gallimard, 1987.

MULLER, J.-W. (Ed.). Memory and Power in Post-War Europe. New York: Cambridge, 2004.

NEUMANN, I. The Uses of Other: "The East" in European Identity Formation. Minneapolis: University of Minnesota Press, 1999.

RICOEUR, P. Tempo e Narrativa. Campinas: Papirus, v. III, 1997.

RICOEUR, P. A memória, a história e o esquecimento. Campinas: UNICAMP, 2007.

RUGGIE, J. The Past as Prologue?: Interests, Identity, and American Foreign Policy. International Security, v. 21, n. 4, p. 89-125, Outono 1997.

TRACHTENBERG, M. The cold war and after: History, Theory, and the logic of International Politics. Princeton: Princeton University Press, 2012.

TROTSKY, L. Is the time ripe for the slogan: "The United States of Europe. Pravda, Moscou, junho 1923. VERNANT, P. El Hombre griego. Madrid: Alianza Editorial, 1993.

Recebido em: 14 jun. 2015 Aceito em: 28 out. 2015 